\title{
Food Insecurity and Coping Strategies among African American Women Living with HIV/AIDS on Antiretroviral Therapy in Rural Alabama
}

\section{Andrew A Zekeri*}

Tuskegee University, Tuskegee, Alabama, USA

\begin{abstract}
Background: As an extension of previous research in rural Alabama on HIVIAIDS, the purpose of this study is to assess the prevalence of food insecurity among African American women living with HIVIAIDS and examine the coping strategies they use to get food for themselves and their children.
\end{abstract}

Methods: Quantitative and qualitative methods were used in the study. Two hundred and fifty African American women living with HIVIAIDS were recruited from two HIVIAIDS clinics and interviewed about food insecurity and coping strategies.

Results: The findings showed that most of the women were food insecure and used numerous strategies to cope with food insecurity. The strategies included receiving food from food banks, supplemental Nutrition Assistance Program, receiving food from family members and friends, making cheaper meals, food from churches, and reducing the amount food cooked for meals. The food insecure women were more likely to be depressed and suffer from psychological distress than do others. Food insecurity is a barrier to medication adherence among these women living with HIVIAIDS.

Conclusion: These findings suggested that addressing food insecurity should be a significant issue in HIVIAIDS treatment and prevention programs in the $21^{\text {st }}$ Century. There is a need for continuous monitoring of food insecurity among people living with AIDS by health care providers in their education to promote adherence to medications and health well-being.

Keywords: Food insecurity; Coping strategies; African American women; HIV/AIDS; Rural Alabama; Antiretroviral therapy

\section{Introduction}

Food insecurity (i.e., uncertain of having, or unable to acquire, enough food because of insufficient money or other resources) is common among people living with HIV/AIDS in Sub Saharan Africa, the United States and Canada [1-22]. The World Health Organization (WHO) indicated that food insecurity is also a leading public health care challenge and may affect adherence to antiretroviral drugs and thus hinder the management of HIV/AIDS disease [2,12-15]. Yet, little is known about food insecurity among African American Women living with HIV/AIDS rural Alabama. Despite the disproportionate impact of HIV infection on racial and ethnic minorities in rural Alabama struggling with many social and economic challenges, such as poverty, substance abuse, unequal access to health care, there is no data on how HIV-infected individuals in this region cope with food insecurity. Past studies largely overlooked strategies used to cope with food insecurity focusing instead on factors associated with food insecurity [1-3,6,11,13-17].

Therefore, as an extension of previous research [20,23,24], the purpose of this study is to assess the prevalence of food insecurity among African American women living with HIV/AIDS and their coping strategies.

\section{Methodology}

The present study is part of a longitudinal qualitative and quantitative research examining HIV/AIDS and rural health disparities in the Alabama Black Belt Counties, a region disproportionately affected by the HIV/AIDS epidemic. The present cross-sectional study was conducted at an AIDS outreach organization clinics in Alabama. The clinics provide medical and social support services to
HIV-positive patients who live in 23 counties in Southeast Alabama. A convenient sample of $250 \mathrm{HIV}$-positive African American women who were on Antiretroviral Therapy (ART) and recruited by the clinic staff participated in the study. For confidentiality purposes, only the staff of the clinic and the researchers informed the patients of the opportunity to participate in the study. Prior to obtaining informed consent, the purpose, procedures, risks and benefits of the study were explained. Participants were also advised that each respondent would receive a $\$ 15.00$ prepaid debit card as an incentive for participating in the study. All study procedures were reviewed and approved by the Tuskegee University Office of Research Compliance prior to the collection of any data. The study focused on African American women because, although HIV epidemic is disproportionately affecting all racial and ethnic minorities, within these minority populations African American women are particularly affected. The estimated lifetime risk of becoming infected with HIV is 1 in 16 for African American men, and 1 in 32 for African American women, a far higher risk than for people of other ethnic backgrounds or races.

\section{Food Insecurity}

In the survey, food insecurity status was evaluated using the six-

*Corresponding author: Andrew A Zekeri, Professor, Tuskegee University, Department of Psychology and Sociology, Tuskegee, Alabama 36088, USA, Tel: 3334-727-8086; E-mail: zekeri@mytu.tuskegee.edu

Received May 02, 2016; Accepted May 20, 2016; Published May 27, 2016

Citation: Zekeri AA (2016) Food Insecurity and Coping Strategies among African American Women Living with HIVIAIDS on Antiretroviral Therapy in Rural Alabama. J AIDS Clin Res 7: 582. doi:10.4172/2155-6113.1000582

Copyright: () 2016 Zekeri AA. This is an open-access article distributed under the terms of the Creative Commons Attribution License, which permits unrestricted use, distribution, and reproduction in any medium, provided the original author and source are credited. 
item from the 18-item Core Food Security Module (CFSM) designed by the USDA in calculating official food insecurity rates for the United States $[4,23]$. The questions were posed in increasing levels of severity by measuring the dimensions of concern about food quantity and food quality over the last 12 months. Examples of questions include: "I worried whether our food would run out before we got money to buy more," "Did you or the other adults in your household ever cut the size of your meals or skip meals because there wasn't enough money for food?" "Were you ever hungry but did not eat because you couldn't afford enough food?" and "did a child in the household ever not eat for a full day because you couldn't afford enough food?" Each question is qualified by the stipulation that the outcomes are due to financial issues. Using the USDA validated cut points; I considered a household with 0 or 1 affirmative response to the CFSM as food secure and a household with two or more affirmative responses as food insecure.

\section{Coping Strategies with Food Insecurity}

The items on coping strategies to food insecurity were first developed in previous work [23] based on focus group discussions. Focus group discussions involved the identification of coping strategies adopted by mothers who are responsible for household food procurement. Semistructured and focus group interviews were conducted among these patients from June 2008 through August 2014. The interviews reported here were to help determine how HIV-positive food insecure mothers provide the daily necessities of food for themselves, their children and make ends meet. Some of the interviews took place at the clinics and in the patients' homes, providing opportunities to observe the general living conditions. Open-ended questions with probes were used to make interviews resemble conversation as much as possible.

In addition to food insecurity and coping strategies, the author assessed demographic and personal characteristics of HIV-positive patients (income, age, level of education, use of Supplemental Nutrition Assistance Program, employment status, marital status, income; age, and education). Also, receipt of Supplemental Nutrition Assistance Program (SNAP) (formerly known as the Food Stamp Program) was assessed.

\section{Statistical Analysis}

The analysis employs descriptive statistics. All descriptive analyses were performed using Statistical Packages for the Social Sciences (SPSS) version 21.0 computer software program (SPSS Inc., Chicago, IL, USA).

\section{Results}

\section{Quantitative results}

Demographics: More than half (56.3\%) of the women were classified as food insecure (Table 1). The majority (46.5\%) did not complete high school. Regarding household income, 56.6\% earned less than $\$ 10,000$. Nearly half $(49.0 \%)$ were $25-50$ years old. More than a third (31.1\%) were employed, $60 \%$ were divorced and $55.1 \%$ participated in Supplemental Nutrition Assistance Program. The prevalence of food insecurity in this sample was more than three times the national average level in 2013 when $14.3 \%$ of all USA households reported food insecurity [4].

Coping strategies: Of the coping strategies, receiving food from family members and friends, participating in the SNAP program, receiving food from food banks, and receiving food from churches were major ways to cushion food insecurity (Table 2). In addition, most of the food insecure women adopted the strategy of belt-tightening

\begin{tabular}{|c|c|}
\hline Characteristics & Percent \\
\hline \multicolumn{2}{|l|}{ Educational Attainment } \\
\hline Did not complete high school & 46.5 \\
\hline Completed high school or equivalent & 38.7 \\
\hline Some college of post high school training & 10.3 \\
\hline Completed a college degree & 4.5 \\
\hline \multicolumn{2}{|l|}{ Income $\mathrm{a}^{\mathrm{a}}$} \\
\hline Under $\$ 10,000$ & 56.6 \\
\hline$\$ 10,000$ to $\$ 14,000$ & 14.3 \\
\hline$\$ 15,000$ to $\$ 20,000$ & 15.5 \\
\hline \multicolumn{2}{|l|}{ Employment } \\
\hline $19-24$ & 15.0 \\
\hline $25-50$ & 49.0 \\
\hline $50-70$ & 24.1 \\
\hline 70 and above & 11.9 \\
\hline \multicolumn{2}{|l|}{ Marital Status } \\
\hline Married & 25.0 \\
\hline Divorced & 60.0 \\
\hline Never Married & 15.0 \\
\hline \multicolumn{2}{|l|}{$\begin{array}{c}\text { Participation in Supplemental Nutrition Assistance Program } \\
\text { or SNAP }\end{array}$} \\
\hline Yes & 55.1 \\
\hline Food Insecure & 56.3 \\
\hline
\end{tabular}

aPercentage scores do not sum to $100 \%$ because missing data are not reported in the table

Table 1: Sociodemographic characteristics of the sample $(\mathrm{N}=250)$.

\begin{tabular}{|c|c|}
\hline \multicolumn{1}{|c|}{ Coping strategies $^{\text {a }}$} & Percent \\
\hline Receive food from family members and friends & 61.0 \\
\hline $\begin{array}{c}\text { The Supplemental Nutrition Assistance Program or SNAP } \\
\text { Informal Financial Support }\end{array}$ & 65.1 \\
\hline Receive money to buy food from absent fathers & 43.0 \\
\hline Receive money to buy food from boyfriends & 22.0 \\
\hline Receive food from Food Banks & 72.0 \\
\hline Receive food from Churches & 60.0 \\
\hline Melt-Tightening & 62.1 \\
\hline Meduce amount of food cooked for meals & 54.6 \\
\hline
\end{tabular}

Note: Percentages for subcategories will not sum to total percentages because single mothers engage in multiple coping strategies

aSome mothers engage in more than one coping strategy with a category

Table 2: Coping strategies of food insecure women.

(making cheaper meals and reducing the amount of food cooked for meals).

\section{Qualitative results}

\section{Coping strategies:}

Government assistance: Majority of the women interviewed were simply trying their best to live on food stamps. However, many mothers argued that food stamp does not provide sufficient money to buy nutritious foods. This is contrary to the claim by the federal government that food stamps enable poor households to buy nutritionally adequate foods. One mother who is 35 years old said: "I spend all my food stamps money at the beginning of the month and it does not last me all month." Another mother, who is 38 year old expressed that "I found out that food stamps do not last the whole month for me. But they help out a lot." In order to make ends meet, some women do without basic amenities that many people take for granted. Stephanie, a 35 year old divorced 
mother revealed that "I eat a little meat most of the time. However, I try to eat a lot of fruits and vegetables. Healthful diets are very expensive." This statement indicated that healthy food options can be too costly.

Informal food support: Family members provided the means to prevent food insecurity (Table 2). It was common for women to feel most comfortable borrowing or relying on their family members for help. Here is how Mary, a 37 year old woman put it, "when I do not have any food, I usually go to my mother and get some few groceries." Another woman said: "If I get my food stamp money about \$250, I go to the store and spend at least $\$ 60$ easily on food every week. So, the last weeks of the month when I have no more food stamps, I go to my mom and get some few groceries. I can call on my friends and neighbors to help me with some foods and they usually get some for me."

Food from Churches and social agencies: These agencies provided important and valuable resources, at least occasionally, for some of the women interviewed. Some said that they rely on local churches and food banks in order to feed. One mother said: "usually by the end of the month, I am out of everything, I go to the local food bank and churches and they will give me groceries." Another woman who was 38 years old said "I cook creatively and visit food banks or charities, and eat food with friends or relatives. I also go to the Food Basket and the Churches for some fruits and vegetables that are expensive at the grocery stores. They help a lot.'

Belt-tightening: Stephanie revealed that she ate out very rarely. She said that "I try to be healthful in my diet and eat low fat foods. Unfortunately, those foods are expensive." A woman who was 40 years old said that "I have only one gallon of milk, a loaf of bread, and some apple juice. I have to be creative about what I make for my children to eat. Sometimes we cut the size of our meals or skip meals because there is not enough food. There haven't been any meat, fruits and vegetables for the past one week."

Psychological distress and religion: The focus group discussions indicated that food insecure women were more likely to be depressed and suffer from more psychological distress than do others. They reported more psychological distress and anxious moods when they were interviewed than did the other women who are food secure. Some reported physical ailments such as headaches, insomnia, exhaustion, and depression from stress. Prayer and a belief in God helped some patients cope with stresses of being poor, food insecure, and having HIV. Many believed that the Lord is going to look out for them. Here we found out religion gives meaning to life.

Adherence to treatment: During the interviews I found that the consequences of food insecurity can affect adherence to treatment [16]. Some women indicated that unaffordability of healthy food was an overarching barrier to adherence to treatment. Some said that because some of their HIV medicines require taking them with food, they skip taking them when they don't food. Tamika, a 40 year old woman frankly told of various time she skipped her medication because she has no food. "I usually don't take my many medicines when I cannot afford healthy good foods. The medicines will make you sick in the stomach. Therefore, I do not take me medicines regularly as prescribed."

\section{Discussion}

Over half of these poor women living with HIV/AIDS are food insecure which is more than that of the general United States population. This high prevalence is also similar to the findings of other previous research among HIV-infected individuals $[7,13-17,19]$. These findings provide insights into the precarious situations poor women living with HIV/AIDS in rural Alabama face and suggest that HIVinfected persons are at risk of food insecurity.

No previous study to my knowledge has examined strategies used to cope with food insecurity in a sample of women living with HIV/ AIDS in the United States. This is one of the first to examine strategies food insecure HIV-positive African American mothers in the United States use to solve their food problem, such as SNAP, food from family members and friends, receiving food from food banks and churches, and belt-tightening. The results suggest that SNAP figured prominently among the actions used by these African American living with HIV/ AIDS to deal with food insecurity. However, many of the women interviewed did not receive enough food stamps. Despite the claim by the federal government that food stamps enable poor households to buy nutritionally adequate food, many of the patients said that the money from food stamp was not enough to buy nutritious food, suggesting that food insecurity can be an important factor in poor HIV/AIDS clinical outcomes.

This study revealed that African American women living with HIV/AIDS experience food problems. They worried if they have enough food in the house. They have challenges regarding the means of getting well balanced meals which is important in the management of HIV infection. The food situation is usually fraught with emotion and tension. Not surprisingly, then, food insecure patients are more likely to report low self-esteem and depressive symptoms than those who are not food insecure. Therefore, provision of food for the patients should be a basic component of care programs for those living with HIV/AIDS.

Another interesting finding is that, as expected, many of the patients are participating in SNAP that was established to alleviate food insecurity among low-income individuals [5]. SNAP participation offered some degree of protection against food insecurity.

\section{Food insecurity, quality of life and infection control}

Focus group discussions suggest that food insecurity can be an important barrier to quality of life and infection control among HIVpositive individuals. Though food is recommended for absorption and optimal benefits for certain ART medicines, food insecurity can reduce medication adherence. Some food insecure women miss their medications when food is unavailable. This can affect the viral suppression that under spins optimal health for HIV-positive individuals. Therefore, food insecurity as a correlate of antiretroviral success must be addressed by HIV clinicians.

\section{Strategies to alleviate food insecurity among HIV-infected individuals}

This qualitative study suggests that clearly, systematic and sustained actions on federal, state, and community level is needed to reduce food insecurity. HIV-Infected Women should have access to and use of federal and community food and nutrition assistance programs that included federal programs such as SNAP, Women, Infant, and children (WIC) School Breakfast Programs (SBP), and National School Lunch Program (NSLP); and assorted community and emergency food assistance programs such as food pantries, food bank and church programs. Most of the food banks have their own web sites that describe ways to access them. They should also be advised to use alternative food sources that included buying from Community Farmers Markets especially in rural areas without ready access to retail food stores or reliable transportation.

HIV-Infected individuals should be advised to draw on their 
Citation: Zekeri AA (2016) Food Insecurity and Coping Strategies among African American Women Living with HIV/AIDS on Antiretroviral Therapy in Rural Alabama. J AIDS Clin Res 7: 582. doi:10.4172/2155-6113.1000582

social capital, their relationships with friends, neighbors, and others within their community because this may impact their ability to access community resources including small food businesses run from community homes.

\section{Stigma}

It is important to learn that some participants were not comfortable visiting food banks and using SNAP because of the stigma associated with food charity. This deterred some women even in times of need because they felt they were been discriminated by workers. Most of the women report shame associated with using SNAP.

\section{Conclusion}

The in-depth interviews and focus group discussions highlight the food situation of African American women who are HIV-positive living in Alabama's Black Belt Counties, a region that is among the poorest in the United States. The results of this study highlight the important need for interventions that address food insecurity for future HIV treatment. Food insecurity should be treated as a health issue that should concern not only social scientists, but also clinicians involved in HIV/AIDS care and support programs. Food insecurity should be integrated into the existing HIV/AIDS intervention programs because it is one of the many facets of poverty that are related to non-adherence to medications. There is a need for continuous monitoring of food insecurity among people living with HIV/AIDS by health care providers in their education to promote adherence to medications and general health well-being. Given to the prominence of poverty among HIV-Positive individuals in the study region, access to food should be clearly assessed and given priority when prescribing HIV medications. Any dietary suggestion a patient is given should be tailored to realistically fit his or her lifestyle and resources.

\section{Limitations of the Study}

These findings should be interpreted in light of the study limitations. First, the study relied on a convenient sample of African American Women living with HIV/AIDS in rural Alabama that cannot be considered a representative of people living with HIV. The cross-sectional design of the study limits interpretation of results.

\section{Competing Interest}

The author declares that he has no competing financial interests or potential conflicts of interest.

\section{Acknowledgement}

I am most grateful to the women who shared their stories, time and commitment, thus enabling me to complete this research. They are so dear to me, and I owe them immeasurably. They helped me understand the experience of living with HIVIAIDS. I want to thank Prof. David Nii Tackie and the three anonymous reviewers at AIDS and Clinical Research Journal for their comments and suggestions.

\section{References}

1. Anema A, Vogenthaler N, Frongillo EA, Kadiyala S, Weiser SD (2009) Food insecurity and HIVIAIDS: Current knowledge, gaps, and research priorities. Curr HIVIAIDS Rep 6: 224-231.

2. Anema A, Weiser SD, Fernandes KA, Ding E, Brandson EK, et al. (2011) High prevalence of food insecurity among HIV-infected individuals receiving HAART in a resource-rich setting. AIDS Care 23: 221-230.

3. Carter KN, Kruse K, Blakely T, Collings S (2011) The association of food security with psychological distress in New Zealand and any gender differences. Soc Sci Med 72: 1463-1471.

4. Coleman-Jensen A, Gregory CC, Singh A (2013) Household food insecurity in the United States in 2013. Department of Agriculture, Economic Research Service, Washington, DC.
5. Heflin CM, Siefert K, Williams DR (2005) Food insufficiency and women's mental health: findings from a 3 year panel of welfare recipients. Soc Sci Med 61: 1971-1982.

6. Landers PS (2007) The Food Stamp Program: History, nutrition education and impact. J Am Diet Assoc 107: 1945-1951.

7. Normén L, Chan K, Braitstein P, Anema A, Bondy G, et al. (2005) Food insecurity and hunger are prevalent among HIV-positive individuals in British Columbia, Canada. J Nutr 135: 820-825.

8. Olson CM (2005) Food insecurity in women: A recipe for unhealthy trade-offs. Top Clinical Nutrition. 20: 321-328.

9. Olson CM, Anderson K, Kiss E, Lawrence F, Selling S (2004). Factors protecting against and contributing to food insecurity among rural families, Family Economics and Nutrition Review 16: 12-20.

10. Siefert K, Heflin CM, Corcoran ME, Williams DR (2001) Food insufficiency and the physical and mental health of low-income women. Women Health 32: 159177.

11. Stuff JE, Casey PH, Szeto KL, Gossett JM, Robbins JM, et al. (2004) Household food insecurity is associated with adult health status. J Nutr 134: 2330-2335.

12. Tsai AC, Bangsberg DR, Emenyonu N, Senkungu JK, Martin JN, et al. (2011) The social context of food insecurity among persons living with HIVIAIDS in rural Uganda. Soc Sci Med 73: 1717-1724.

13. Tiyou A, Belachew T, Alemseged F, Bladgilign S (2012) Food insecurity and associated factors among HIV-Infected individuals receiving highly active antiretroviral therapy in Jimma Zone Southwest Ethiopia. Nutrition Journal 11: 51.

14. Tsai AC, Bangsberg D, Frongillo EA, Hunt PW, Muzoora C, et al. (2012) Food insecurity, depression and the modifying role of social support among people living with HIVIAIDS in rural Uganda. Social Science and Medicine 74: 2012 2019.

15. Weiser SD, Fernandes KA, Brandson EK, Lima VD, Anema A, et al. (2009) The association between food insecurity and mortality among HIV-infected individuals on HAART. J Acquir Immune Defic Syndr 52: 342-349.

16. Weiser SD, Frongillo EA, Ragland K, Hogg R, Riley E, et al. (2009) Food insecurity is associated with incomplete HIV RNA suppression among homeless and marginally housed HIV-Infected individuals in San Francisco. Journal of General Internal Medicine 24: 14-20.

17. Weiser SD, Tsai AC, Gupta R, Frongillo EA, Kawuma A, et al. (2012) Food insecurity is associated with morbidity and patterns of healthcare utilization among HIV-infected individuals in a resource-poor setting. AIDS 26: 67-75.

18. Wu DY, Munoz M, Espiritu B, Zeladita J, Sanchez E, et al. (2008) Burden of depression among impoverished HIV-Positive women in Peru. Journal of Acquired Immune Deficiency Syndromes 48: 500-504.

19. Vozoris NT, Tarasuk VS (2003) Household food insufficiency is associated with poorer health. J Nutr 133: 120-126.

20. Zekeri AA, Nnedu C (2015) Food insecurity and psychological factors among African American Women living with HIV on antiretroviral drugs in rural Alabama. National HIV Prevention Conference, Atlanta, GA.

21. Zekeri AA (2013) Educational attainment and self-rated health status among single mothers in rural Alabama. Psychol Rep 113: 1187-1191.

22. Zekeri AA (2010) Household food insecurity and depression among single mothers in Rural Alabama. Journal of Rural Social Sciences 25: 90-102.

23. Zekeri AA (2007) Livelihood strategies of food-insecure poor, female-headed families in rural Alabama. Psychol Rep 101: 1031-1036.

24. Zekeri AA, Diabate $Y$ (2014) Food insecurity and psychological well-being among women living with HIVIAIDS on anti-retroviral therapy in the Alabama Black Belt. Professional Agricultural Workers Journal 2. 